\title{
Theoretical and Experimental Investigation of Fiber Bragg Gratings With Different Lengths for Ultrasonic Detection
}

\author{
Zhouzhou YU, Qi JIANG*, Hao ZHANG, and Junjie WANG \\ School of Control Science and Engineering, Shandong University, Jinan, 250061, China \\ State Key Lab of Microbial Technology, School of Life Science, Shandong University, Jinan, 250100, China \\ *Corresponding author: Qi JIANGＥmail: jiangqi@sdu.edu.cn
}

\begin{abstract}
In this paper, the response of fiber Bragg gratings (FBGs) subjected to the ultrasonic wave has been theoretically and experimentally investigated. Although FBG sensors have been widely used in the ultrasonic detection for practical structural health monitoring, the relationship between the grating length and ultrasonic frequency is not yet to be obtained. To address this problem, an ultrasound detection system based on FBGs is designed and the response sensitivity of different lengths gratings are detected. Experimental results indicate that the grating with $3 \mathrm{~mm}$ length has a higher sensitivity when detecting high frequency ultrasonic wave, and the amplitude can be up to 0.6 $\mathrm{mV}$. The $10 \mathrm{~mm}$ length grating has better detection sensitivity for low frequency ultrasonic wave and the amplitude is $0.8 \mathrm{mV}$. The results of this analysis provide useful tools for high sensitivity ultrasound detection in damage detection systems.
\end{abstract}

Keywords: FBG; nondestructive testing; ultrasonic detection

Citation: Zhouzhou YU, Qi JIANG, Hao ZHANG, and Junjie WANG, "Theoretical and Experimental Investigation of Fiber Bragg Gratings With Different Lengths for Ultrasonic Detection,” Photonic Sensors, 2016, 6(2): 187-192.

\section{Introduction}

The ultrasonic detection based on fiber Bragg gratings (FBGs) is a new nondestructive testing technology being developed in recent years [1]. The basic idea is to use FBG sensors as ultrasonic detectors to analyze the injury condition of the construction. Compared with classical electronic detection sensors, FBGs have unique advantages such as immunity to electromagnetic interference, lightweight, high temperature corrosion resistance, stability, and durability in harsh environment. FBGs-based ultrasonic sensors have been indicated as the ideal candidate for practical structural health monitoring in light of their unique advantages over conventional sensing devices $[2,3]$.
At present, the use of FBG sensors for the detection of ultrasound has been widely reported in literature. Sorazu presented the results of theoretical and experimental investigations into the interaction between ultrasonic waves and fiber optic sensors, focusing on the birefringence introduced within an optical fiber placed with its axis parallel to the ultrasonic wave front [4]. Lam proposed that fiber Bragg grating sensors could be embedded in the laminate material to detect the signal of ultrasonic Lamb wave, and the damage assessment of the composite material could be found out [5]. Lee designed a new type of FBG ultrasonic receiver based on the embedded system, which detected the impact damage of carbon fiber reinforced plastic laminates by shockwave. They described the design

Received: 10 December 2015 / Revised: 7 March 2016

C The Author(s) 2016. This article is published with open access at Springerlink.com

DOI: $10.1007 / \mathrm{s} 13320-016-0307-y$

Article type: Regular 
of the structure of the FBG sensors and analyzed characteristics of the ultrasonic [6]. The FBG performance has a great influence on the test results, Liu and Han investigated the affection of the FBG sensors directivity, and their analysis revealed several unique FBG response characteristics [7]. Wild presented results for the spatial performance of fiber Bragg grating sensors to continuous-wave acousto-ultrasonic (AU) signals [8]. However, these researches mainly focused on health monitoring, location defection, and damage degree evaluation of the material structure [9]. There were only a few studies concerning the effect of different grating lengths on the sensitivity. The relationship between the grating length and ultrasonic frequency has not a clear conclusion.

Based on this argument, an ultrasound detection system based on FBGs is designed in this paper, and the response of FBGs to the ultrasonic wave is investigated in terms of gratings length changes. The results of the experiment have a good effect, meanwhile the qualitative relationship between the grating length and ultrasonic frequency is obtained.

\section{Theoretical analysis}

In this section, the interaction between the Bragg grating length and ultrasonic wave frequency is theoretically analyzed. FBGs consist of a periodic modulation of the refractive index in the core of a single mode fiber. According to the mode coupling theory, the central wavelength of the reflected narrowband light namely $\lambda_{B}$ can be described by the Bragg condition [8]:

$$
\lambda_{B}=2 n_{\text {eff }} \Lambda
$$

where $n_{\text {eff }}$ is the effective refractive index of the optical mode propagating along the fiber, and $\Lambda$ is the periodicity of the grating. When the Bragg condition is satisfied, the FBG reflects a narrow band of wavelengths, creating a stop band in the transmission spectrum and all of the other wavelengths not meeting the resonant condition are transmitted. The resonance depends on the periodicity of the grating and the effective refractive index of the fiber. In all of the external factors, the strain, temperature, and ultrasonic field are the most common factors that cause the Bragg wavelength shift $[10,11]$.

In our hypothesis, the ultrasonic wave can be modeled by a longitudinal strain wave, propagating along the axis of the optical fiber. Moreover, the time dependence is assumed to be sinusoidal. Hence, it can be expressed as an equation:

$$
\varepsilon(t)=\varepsilon_{m} \cos \left(k z-w_{s} t\right)
$$

where $w_{s}$ is the ultrasonic wave frequency, $\varepsilon_{m}$ is the amplitude of sound wave, $z$ is the sound path, and $k=2 \pi / \lambda \mathrm{s}$ is the ultrasonic wave number [12]. The transfer matrix method is utilized to analyze the FBG multilayered structure. When the length of FBG is much smaller than the ultrasonic wavelength, the whole length of the gratings and the refractive index changes caused by the photo elastic effect are uniform [13, 14], and the wavelength shift of the FBG can be given by

$$
\Delta \lambda(t)=\lambda_{B} \varepsilon_{m}\left[1-\left(\frac{n_{\mathrm{eff}}^{2}}{2}\right)\left[p_{12}-v\left(p_{11}+p_{12}\right)\right]\right] \cos \left(w_{s} t\right)
$$

where $v$ is Poisson's ratio, and $p_{11}$ and $p_{12}$ represent elastic coefficient of the material, respectively.

In ultrasonic testing, the length of the grating, the reflectivity, and other parameters have a great influence on the detection of signal. In order to obtain a better detection effect, FBG length is less than $1 / 2$ of the ultrasonic wavelength and its reflectivity is more than $0.9[15,16]$. This can make sure that the FBG can not be affected by the non-uniform stress field of ultrasonic. When the distance between the FBG and the ultrasonic emission source is constant, the relationship between the response amplitude of sensor and the angle is a kind of approximate cosine [10]. The angle is formed by the grating axial and the ultrasonic wave propagation direction. Therefore, the FBG should be arranged in the coaxial direction with the ultrasonic transmission line and avoid the far field. 


\section{Design and analysis of the experimental test system}

\subsection{Design of the experimental test system}

In order to observe the effect of different length gratings for ultrasonic detection, an ultrasound detection system was set up. The test system consisted of the high frequency signal part, the FBG optical sensing detection part, and the computer processing part. Figure 1 presents the specific experimental platform.

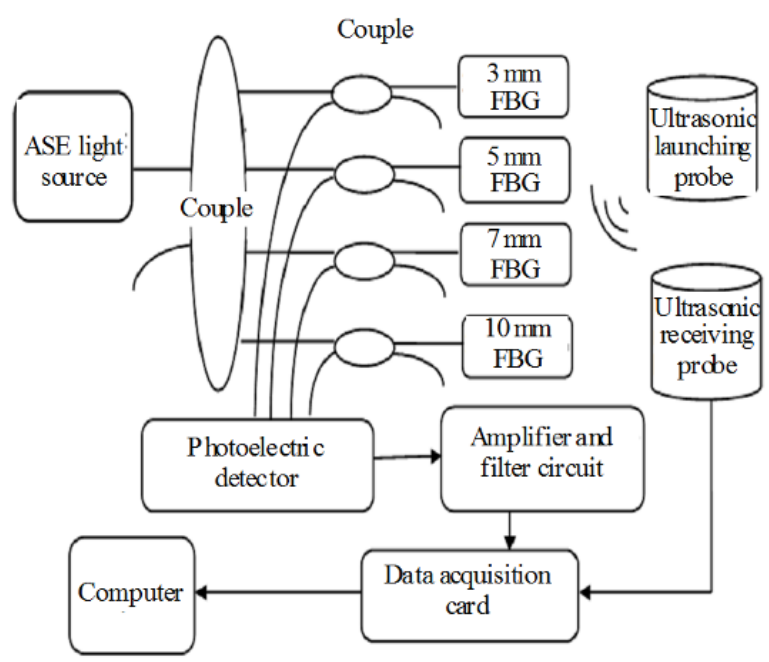

(a)

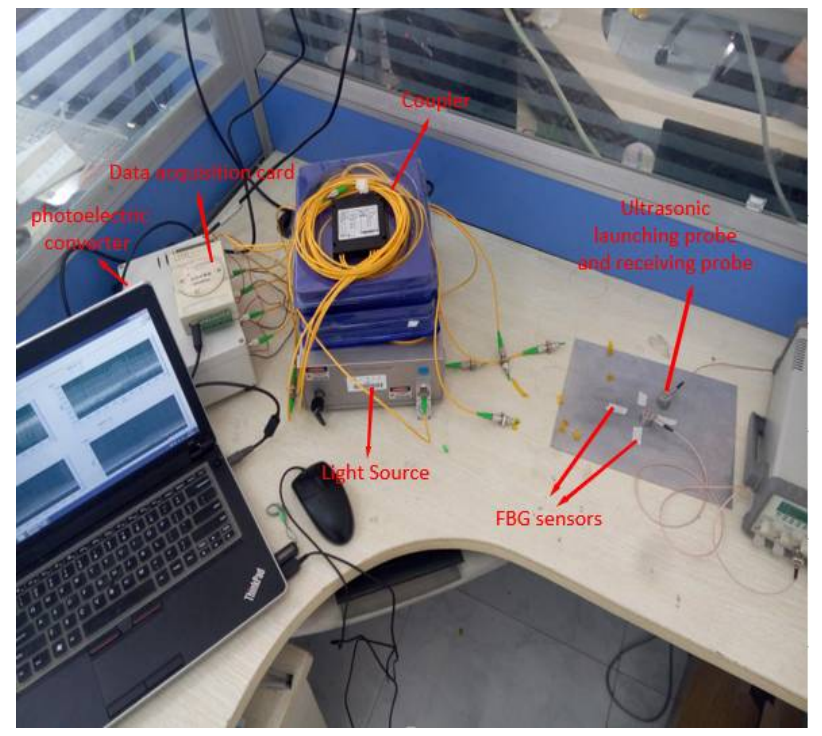

(b)

Fig. 1 Experimental setup for FBG sensing system (a) experimental device flow chart and (b) measurement instrument.
In this test system, the FBGs and the ultrasonic transducers were all surface-attached to the aluminum alloy plate. The grating lengths were $3 \mathrm{~mm}, 5 \mathrm{~mm}, 7 \mathrm{~mm}$, and $10 \mathrm{~mm}$. The $3 \mathrm{~dB}$ bandwidths were $0.524 \mathrm{~nm}, 0.49 \mathrm{~nm}, 0.254 \mathrm{~nm}$, and $0.235 \mathrm{~nm}$, while the reflectivity were $89.38 \%$, $89.06 \%, 91.61 \%$, and $95.28 \%$. All gratings were placed at an equal distance $(100 \mathrm{~mm})$ from the ultrasonic transducers in order to ensure the same acoustic amplitude. Specific layout position is shown in Fig. 2. The responses of different length gratings excited under the same frequency ultrasonic input wave were detected with their frequency range from $100 \mathrm{kHz}$ to $800 \mathrm{kHz}$. Furthermore, the resonant piezoelectric sensor was measured at the same time. In order to make sure the experiment goes well, the temperature of the room was monitored and held constantly at $21^{\circ} \mathrm{C}$. So the effects of temperature changes were eliminated.

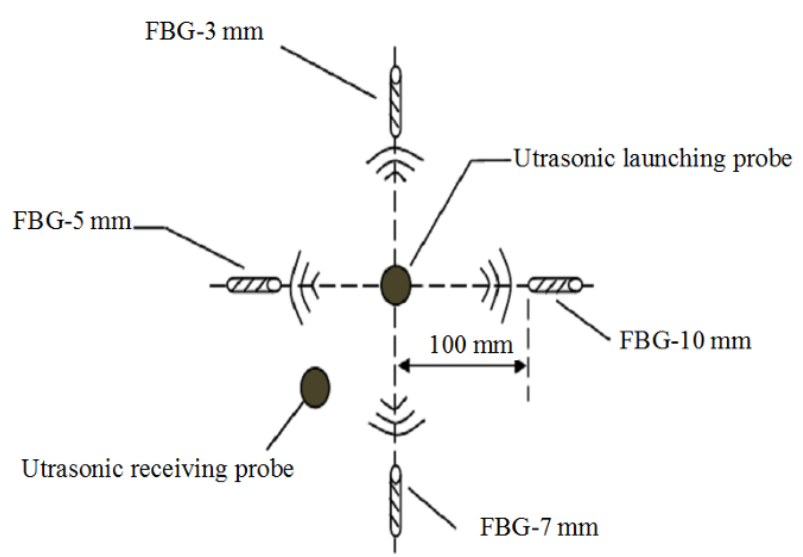

Fig. 2 Position of FBG sensors and the ultrasonic transducers.

\subsection{Analysis and results}

In the experiment, the ultrasonic frequency range from $100 \mathrm{kHz}$ to $800 \mathrm{kHz}$ and the data were detected at a $100 \mathrm{kHz}$ interval. Under the $400 \mathrm{kHz}$ frequency excitation, the signal responses of five sensors channels $(3 \mathrm{~mm}, 5 \mathrm{~mm}, 7 \mathrm{~mm}, 10 \mathrm{~mm}$, and ultrasonic receiving probe) were obtained. After filtered and Fourier transformed by MATLAB software, the time and frequency domains of response are shown in Fig. 3. 

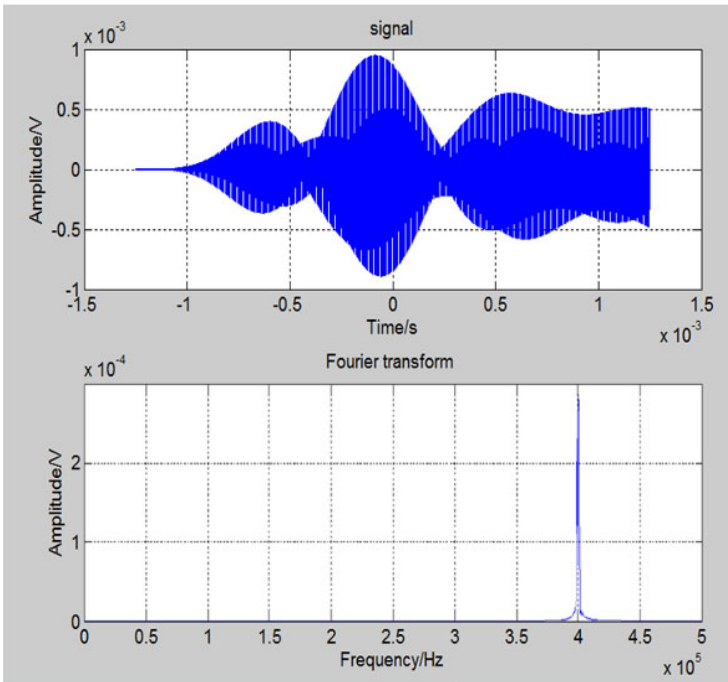

(a)
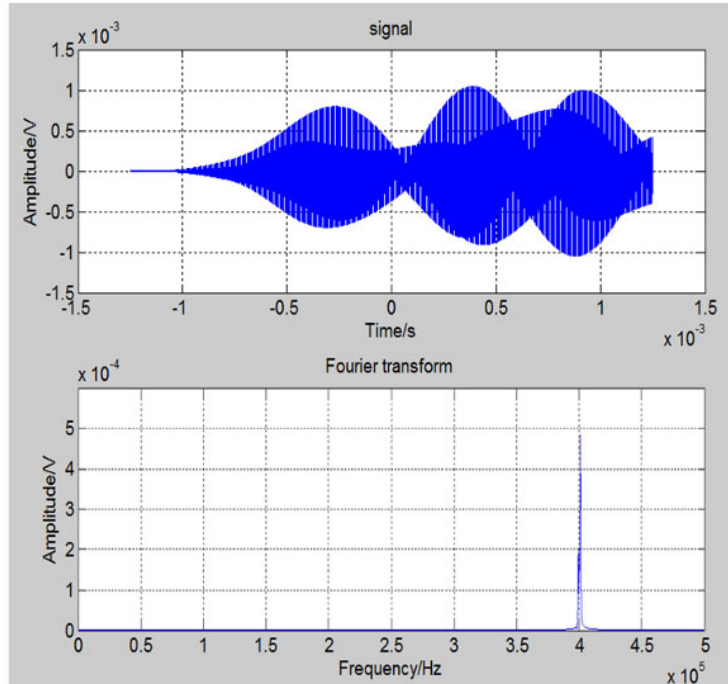

(b)
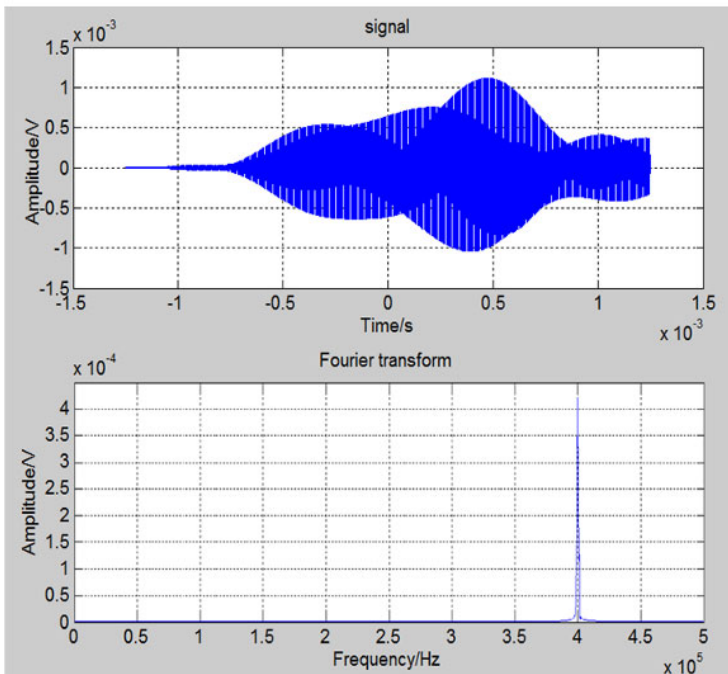

(c)

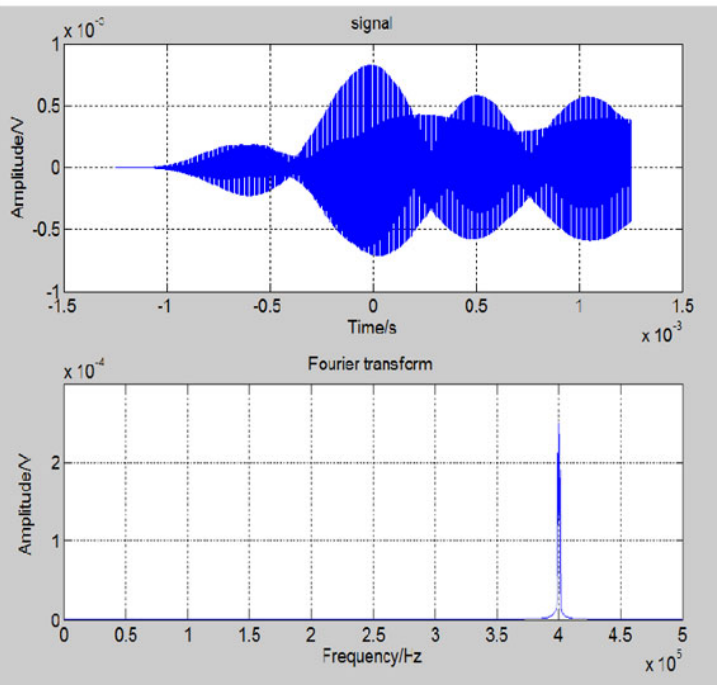

(d)

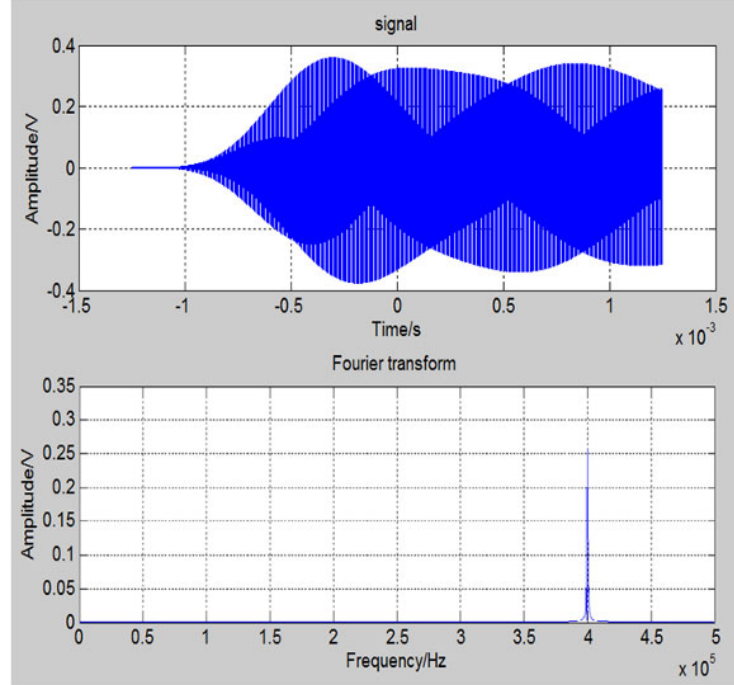

(e)

Fig. 3 Time and frequency domains of signal responses: (a) $3 \mathrm{~mm}$ FBG sensor, (b) $5 \mathrm{~mm}$ FBG sensor, (c) $7 \mathrm{~mm}$ FBG sensor, (d) $10 \mathrm{~mm}$ FBG sensor, and (e) ultrasonic receiving probe.

Since the FBG sensors have a smaller contact area than the piezoelectric sensor with the aluminum, the response amplitude detected by ultrasonic receiving probe was much larger than the grating detection. Using the origin to integrate data as shown in Fig. 4, we could see that gratings with $5 \mathrm{~mm}$ and $7 \mathrm{~mm}$ length had obvious effect under $400 \mathrm{kHz}$ ultrasonic excitation, and the detection amplitude of $7 \mathrm{~mm}$ grating could be up to $1.2 \mathrm{mV}$.

The excitation signal was applied from $100 \mathrm{kHz}$ to $800 \mathrm{kHz}$ in turn, and the eight groups of data are presented in Table 1 and Table2. 


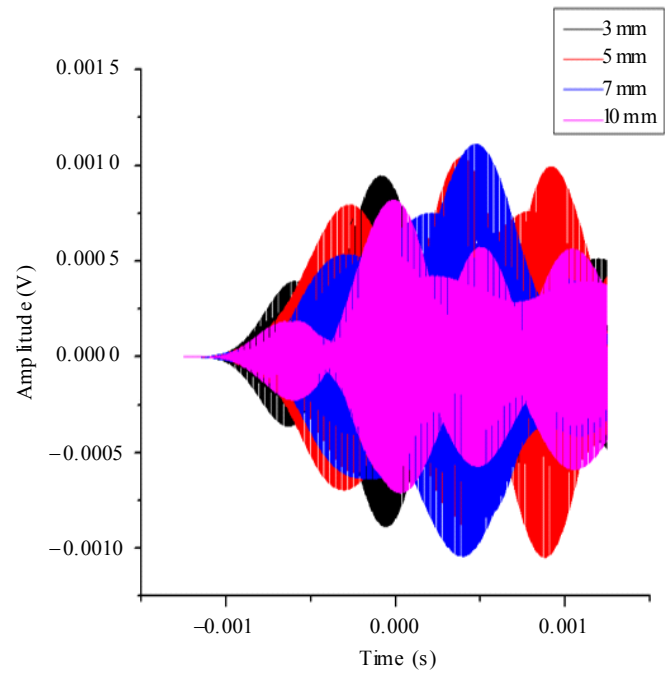

Fig. 4 Integrate data of sensors detection in five channels.

Table 1 Results of ultrasonic signal detection in five channels.

\begin{tabular}{|c|c|c|c|c|c|}
\hline Frequercy & $3 \mathrm{~mm}$ & $5 \mathrm{~mm}$ & $7 \mathrm{~mm}$ & $10 \mathrm{~mm}$ & $\begin{array}{l}\text { Ultrasonic } \\
\text { receiving } \\
\text { probe }\end{array}$ \\
\hline $100 \mathrm{kHz}$ & 5 & 5 & 11 & 8 & 2500 \\
\hline $200 \mathrm{kHz}$ & 9 & 9 & 8 & 6 & 4000 \\
\hline $300 \mathrm{kHz}$ & 4 & 4 & 6.5 & 5 & 3500 \\
\hline $400 \mathrm{kHz}$ & 9 & 9 & 11 & 12 & 6500 \\
\hline $500 \mathrm{kHz}$ & 2.5 & 2.5 & 2.8 & 6.5 & 3500 \\
\hline $600 \mathrm{kHz}$ & 1.5 & 1.5 & 1.8 & 2.6 & 3500 \\
\hline $700 \mathrm{kHz}$ & 2 & 2 & 4 & 2.2 & 1500 \\
\hline $800 \mathrm{kHz}$ & 6 & 6 & 2 & 3.5 & 2000 \\
\hline
\end{tabular}

Table 2 Normalization process of the data.

\begin{tabular}{|c|c|c|c|c|c|}
\hline $\begin{array}{r}\text { The length of } \\
\text { Frequercy }\end{array}$ & $\begin{array}{c}\text { Data } \\
\text { processing }\end{array}$ & $3 \mathrm{~mm}$ & $5 \mathrm{~mm}$ & $7 \mathrm{~mm}$ & $10 \mathrm{~mm}$ \\
\hline $100 \mathrm{kHz}$ & 2.5 & 2.5 & 2.5 & 2.5 & 2.5 \\
\hline $200 \mathrm{kHz}$ & 4 & 2.5 & 1.8 & 1.9 & 2.2 \\
\hline $300 \mathrm{kHz}$ & 3.5 & 2 & 1.5 & 1.6 & 2.5 \\
\hline $400 \mathrm{kHz}$ & 6.5 & 4.5 & 2.5 & 3.75 & 2.2 \\
\hline $500 \mathrm{kHz}$ & 3.5 & 1.25 & 0.6 & 2 & 1.25 \\
\hline $600 \mathrm{kHz}$ & 3.5 & 0.75 & 0.4 & 0.8 & 1.4 \\
\hline $700 \mathrm{kHz}$ & 1.5 & 1 & 0.9 & 0.69 & 0.7 \\
\hline $800 \mathrm{kHz}$ & 2 & 1.5 & 0.45 & 1.1 & 0.69 \\
\hline
\end{tabular}

The data detected by the ultrasonic probe were compared with FBGs, and the relationship between the normalized FBG response and the ultrasonic frequency is shown in Fig. 5 .

The experimental results of four grating sensors and the ultrasonic transducer showed very similar trends in both sensitivity and directivity. Although FBG sensors had a weak response amplitude, they were still showing high sensitivity for ultrasonic detection. In addition, when the range of frequency was from $100 \mathrm{kHz}$ to $800 \mathrm{kHz}$, the grating with a $3 \mathrm{~mm}$ length had the highest sensitivity, and when the detection frequency was $800 \mathrm{kHz}$, the amplitude could be up to $0.6 \mathrm{mV}$. The $10 \mathrm{~mm}$ length of the grating had the highest sensitivity when the detecting frequency was low, and the amplitude was $0.8 \mathrm{mV}$ as the frequency was $100 \mathrm{kHz}$. The gratings with the length of $5 \mathrm{~mm}$ and $7 \mathrm{~mm}$ had a better detection sensitivity for intermediate frequency ultrasonic wave.

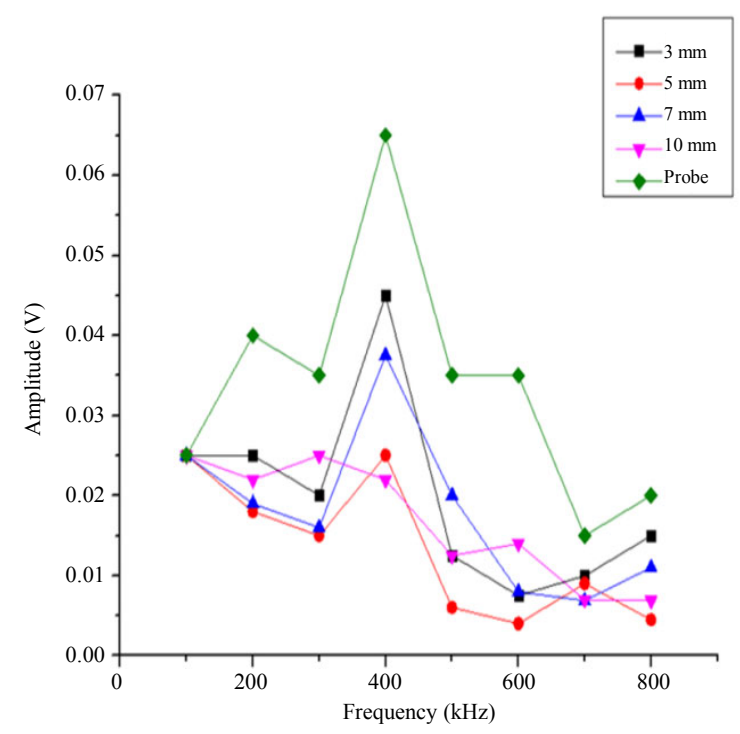

Fig. 5 Normalization of data.

\section{Conclusions}

In this paper, an ultrasound detection system based on FBGs is designed to analyze the effects of the grating length on the quality of ultrasonic resonance. The detection of different frequency ultrasonic signals in the aluminum plate is further explored, and a clear relationship between the grating length and ultrasonic frequency is obtained. Quantitative analysis has been carried out for uniform gratings, showing a better suitability in using gratings as ultrasound detectors. The theoretical analysis would be useful for sensitivity improvement of the FBG-based ultrasonic and acoustic emission sensing system. Because this experiment is a preliminary study on the response sensitivity of different length gratings to detect different wavelengths ultrasonic, deficiencies cannot be avoided in the experimental plan, which will be optimized in the further research. 


\section{Acknowledgment}

This work was financially supported by the National Natural Science Foundation of China (No. 61271073 and No. 61473175) and was supported by the Fundamental Research Funds of Shandong University (No. 2015JC040).

Open Access This article is distributed under the terms of the Creative Commons Attribution 4.0 International License (http://creativecommons.org/licenses/by/4.0/), which permits unrestricted use, distribution, and reproduction in any medium, provided you give appropriate credit to the original author(s) and the source, provide a link to the Creative Commons license, and indicate if changes were made.

\section{References}

[1] Y. Tan, L. Meng, and D. Zhang, "Strain sensing characteristic of ultrasonic excitation-fiber Bragg gratings damage detection technique," Measurement, 2013, 46(1): 294-304.

[2] Z. LI, M. Xu, J. Tang, Y. Chen, and Y. Zhao, “A study of signal demodulation techniques in a fiber Bragg grating sensing system," Industrial Instrumentation and Automation, 2005, (3): 12-16.

[3] V. Italia, A. Cusano, S. Campopiano, A. Cutolo, and M. Giordano, "Analysis of the phase response of fiber Bragg gratings to longitudinal ultrasonic fields in the high frequency regime: towards new interrogation strategies," in Proceedings of 2005 IEEE/LEOS Workshop on Fibers and Optical Passive Components, Italy, pp. 389-392, 2005.

[4] B. Sorazu, G. Thursby, and B. Culshaw, "Wavefront integrating fiber sensors for ultrasonic detection," IEEE Sensors Journal, 2011, 11(7): 1623-1631.

[5] P. M. Lam, K. T. Lau, H. Y. Ling, Z. Su, and H. Y. Tam, "Acousto-ultrasonic sensing for delaminated GFRP composites using an embedded FBG sensor," Optics \& Lasers in Engineering, 2009, 47(10): 1049-1055.

[6] J. Lee, H. Tsuda, and N. Toyama, "Impact wave and damage detections using a strain-free fiber Bragg grating ultrasonic receiver," NDT \& E International, 2007, 40(1): 85-93.

[7] T. Liu and M. Han, "Analysis of fiber Bragg gratings for ultrasonic detection," IEEE Sensors Journal, 2012, 12(7): 2368-2373.

[8] G. Wild and S. Hinckley, "Spatial performance of acousto-ultrasonic fiber Bragg grating sensor," IEEE Sensors Journal, 2010, 10(4): 805-806.

[9] H. Zhu, J. Yu, and J. Zhang, "A summary review and advantages of vibration-based damage identification methods in structural health monitoring," Engineering Mechanics, 2011, 28(2): 1-6.

[10] T. Erdogan, "Fiber grating spectra," Journal of Lightwave Technology, 1997, 15(8): 1277-1294.

[11] M. Majumder, T. K. Gangopadhyay, A. K. Chakraborty, K. Dasgupta, and D. K. Bhattacharya, "Fiber Bragg gratings in structural health monitoring-present status and applications," Sensors and Actuators A: Physical, 2008, 147(1): 150-164.

[12] J. Song, Q. Jiang, Y. Huang, Y. Li, Y. Jia, X. Rong, et al., "Research on pressure tactile sensing technology based on fiber Bragg grating array," Photonic Sensors, 2015, 5(3): 1-10.

[13] Q. C. Wang, Y. E. Xian-Feng, Y. L. Cao, and L. Y. Zhan, "Detection of focused ultrasonic fields with fiber Bragg grating," Journal of Transcluction Technology, 2005, 18(1): 171-174.

[14] H. Zhang, X. Sun, X. Qi, X. Liu, and H. Dong, "Ultrasonic lamb wave inspection using fiber Bragg gratings," in IEEE 2008 China-Japan Joint Microwave Conference, Shanghai, pp. 805-808, 2008.

[15] G. Coppola, A. Minardo, A. Cusano, G. Breglio, L. Zeni, A. Cutolo, et al., "Analysis of feasibility on the use of fiber Bragg grating sensors as ultrasound detectors," in Proc. SPIE, vol. 4328, pp. 224-232, 2001.

[16] N. E. Fisher, D. J. Webb, C. N. Pannell, D. A. Jackson, L. R. Gavrilov, J. W. Hand, et al., "Ultra-sonic field and temperature sensor based on short in-fiber Bragg gratings," Electronics Letters, 1998, 34(11): 1139-1140. 